ORIGINAL ARTICLE

\title{
Cortisol and growth hormone responses to spontaneous hypoglycaemia in infants and children
}

\section{P M Crofton, P C Midgley}

See end of article for authors' affiliations .....................

Correspondence to: Dr P M Crofton, Department of Paediatric Biochemistry, Royal Hospital for Sick Children, Sciennes Road, Edinburgh EH9 1LF, UK; patricia.crofton@ luht.scot.nhs.uk

Accepted 21 August 2003

\begin{abstract}
Aims: To evaluate responses of cortisol and growth hormone (GH) to spontaneous hypoglycaemia in infants and children.

Methods: Retrospective review of laboratory and clinical data in paediatric patients investigated for suspected hypoglycaemia over a five year period. Thirty patients (16 aged $<3$ months) had hypoglycaemia confirmed by laboratory analysis (glucose $<2.5 \mathrm{mmol} / \mathrm{l}$ ) and were compared with 26 patients ( 11 aged $<3$ months) with glucose $\geqslant 2.5 \mathrm{mmol} / \mathrm{l}$.

Results: The commonest causes of hypoglycaemia were transient hyperinsulinism in infants $<3$ months and intercurrent infection in those $>6$ months of age. In both hypo- and non-hypoglycaemic patients, cortisol was positively $\left(r_{\mathrm{s}}+0.66\right.$ and +0.68$)$ and $\mathrm{GH}$ inversely $\left(r_{\mathrm{s}}-0.65\right.$ and -0.75$)$ correlated with age. Hypo- and non-hypoglycaemic infants $<3$ months had median cortisol concentrations of 205 and $116 \mathrm{nmol} / \mathrm{I}$ respectively compared with 1370 and $736 \mathrm{nmol} / \mathrm{l}$ in hypo- and non-hypoglycaemic children $>6$ months. Conversely, median $\mathrm{GH}$ was 46.5 and $51.2 \mathrm{mU} / \mathrm{l}$ in hypo- and non-hypoglycaemic infants compared with 14.3 and $12.1 \mathrm{mU} / \mathrm{l}$ in older hypo- and non-hypoglycaemic patients. Older nonhypoglycaemic patients with glucose levels below the glycaemic thresholds established for cortisol and GH secretion in adults had higher cortisol and GH concentrations than patients whose glucose levels exceeded these thresholds.

Conclusions: Cortisol and GH responses to spontaneous hypoglycaemia in children are highly age dependent. Young infants mount a poor cortisol response compared with older infants and children. Children older than 6 months may have glycaemic thresholds for cortisol and $\mathrm{GH}$ similar to those established for adults.
\end{abstract}

$\mathrm{N}$ eonates are recognised to be at high risk of hypoglycaemia. ${ }^{1}$ The aetiology may be multifactorial, including developmental immaturity of the gluconeogenic and ketogenic pathways, poor mobilisation of hepatic glycogen stores, and transient hyperinsulinism. Less common pathological causes include persistent hyperinsulinism, hypopituitarism, adrenal disorders, and fatty acid oxidation defects. $^{1-3}$

For older infants and children, the commonest cause is socalled "ketotic hypoglycaemia" in which hypoglycaemia occurs after a longer fast than usual, or with decreased caloric intake associated with intercurrent illness and vomiting. ${ }^{3}$ Some of these children may have a history of having been born small for gestational age (SGA) or of failure to thrive, and may be at increased risk of developing hypoglycaemia because of low glycogen stores or reduced muscle mass with decreased availability of gluconeogenic substrates. In some children, however, there is an underlying pathological cause such as fatty acid oxidation defects, hyperinsulinism (either endogenous or exogenous), reactive hypoglycaemia (typically occurring 2-3 hours after a meal or feed), adrenal insufficiency, hypopituitarism, or severe liver dysfunction.

It is important that appropriate samples are collected for full biochemical investigation of possible endocrine or metabolic causes at the time of the initial hypoglycaemic episode because it is often difficult to reproduce the hypoglycaemia at a later stage under conditions of controlled fasting. ${ }^{4}$ These samples comprise blood for measurement of glucose, intermediary metabolites, hormones, and amino acids, and the first urine passed after the episode for metabolic investigations including organic and amino acids.
The physiological response to falling blood glucose is a decrease in circulating insulin, increased mobilisation of fatty acids, an increase in fatty acid oxidation with ketone body production, and an increase in the counter-regulatory hormones, including cortisol and GH. In adults, the glycaemic thresholds for activation of cortisol and $\mathrm{GH}$ secretion are 3.2 and $3.7 \mathrm{mmol} / \mathrm{l}$ respectively, ${ }^{5}$ but it is unknown whether these thresholds can be appropriately applied to the paediatric age group. Moreover, interpretation of what constitutes an appropriate cortisol or GH response to spontaneous hypoglycaemia in the paediatric age group remains problematic. Although there is published information on normal cortisol and GH responses to the insulin hypoglycaemia dynamic function test in children, ${ }^{67}$ there are few studies that have examined the responses of these hormones to spontaneous hypoglycaemia which may be of more insidious onset.

We therefore undertook a retrospective review of all patients with suspected hypoglycaemia from whom samples for a hypoglycaemia screen were received by our paediatric referral laboratory over a five year period. Our aims were to examine the responses of cortisol and GH to spontaneous hypoglycaemia occurring in neonates, infants, and children who had no evidence of pituitary or adrenal disorders, and to compare these responses with those observed in age matched patients suspected of hypoglycaemia but in whom hypoglycaemia was not confirmed at the time of sampling.

\footnotetext{
Abbreviations: $\mathrm{ACTH}$, adrenocorticotrophic hormone; $\mathrm{CRH}$, corticotrophin releasing hormone; $\mathrm{GH}$, growth hormone; $\mathrm{HOB}$, 3-hydroxybutyrate; SGA, small for gestational age
} 


\section{PATIENTS AND METHODS Hypoglycaemia screen}

Hypoglycaemia was defined as a laboratory plasma glucose $<2.5 \mathrm{mmol} / \mathrm{l}$. The policy of the laboratory is that a hypoglycaemia screen should be performed for suspected hypoglycaemia occurring after the first day of life in term neonates, after three days of age in preterm neonates, and at any time in older infants and children, to investigate its cause. Babies born to mothers with diabetes are excluded. Blood was collected at the time of suspected hypoglycaemia for biochemical investigation of its cause. Blood was separated within 20 minutes or (if the patient was in an offsite hospital) collected into ice and separated within one hour, then stored in aliquots at $-20^{\circ} \mathrm{C}$ until analysis. The full hypoglycaemia screen comprised: confirmatory laboratory plasma glucose, 3-hydroxybutyrate (HOB), free fatty acids, lactate, insulin ( \pm C-peptide), cortisol, ACTH, GH, free thyroxine, TSH, and amino acids. In addition, ketones, organic acids, amino acids, and reducing substances (with sugar chromatography if positive) were analysed in the first urine sample passed after the episode. The full screen required approximately $4 \mathrm{ml}$ lithium heparin and $0.5 \mathrm{ml}$ fluoride oxalate blood. If insufficient blood was obtained, the priority order was confirmatory laboratory glucose, insulin (if the patient was hypoglycaemic), and/or HOB, cortisol, and GH. Only data for glucose, insulin, HOB, cortisol, and GH are presented here.

\section{Subjects}

All patients in whom hypoglycaemia was suspected on the basis of point-of-care testing and in whom blood was sent to the laboratory for a hypoglycaemia screen within the five year period October 1996 to September 2001 inclusive were eligible for inclusion in the study. We excluded any samples in which there was insufficient blood for cortisol analysis. Fifty nine patients fulfilled these criteria. Subjects were divided into a hypoglycaemic group $(\mathrm{n}=30)$ in whom laboratory analysis confirmed that plasma glucose was $<2.5 \mathrm{mmol} / \mathrm{l}$ and a non-hypoglycaemic group in whom laboratory analysis did not confirm hypoglycaemia (glucose $\geqslant 2.5 \mathrm{mmol} / \mathrm{l}, \mathrm{n}=29$ ). All subjects in the hypoglycaemic group were younger than 4 years. In order to match the age distribution in the two groups, we therefore excluded three older patients (aged 13-15 years) from the non-hypoglycaemic group (remaining, $n=26$ ). Subjects within the hypoglycaemic and non-hypoglycaemic groups were further subdivided into infants younger than 3 months and older than 6 months (there were no infants in the study aged between 3 and 6 months).

For all hypoglycaemic subjects, the results of insulin, HOB and, where appropriate, other clinical and laboratory investigations were examined and clinical case notes were reviewed in order to ascertain retrospectively the cause of the hypoglycaemia. For the hypoglycaemic infants younger than 3 months, gestational age at birth, birth weight, and postnatal age at onset of hypoglycaemia were recorded. Infants were defined as relatively SGA if their birth weight was $<10$ th centile for gestational age. For infants who required intravenous glucose infusion, maximal glucose requirement, age at maximal glucose requirement and, if applicable, age at resolution of hypoglycaemia were recorded.

\section{Methods}

Blood samples were collected into tubes containing fluoride oxalate (for glucose and HOB analysis) and lithium heparin (for insulin, cortisol, and GH analysis).

Plasma glucose was measured urgently within two hours of collection, using a hexokinase assay on the Hitachi 911 analyser (Roche Diagnostics Ltd, Lewes, East Sussex, UK). The between-run coefficient of variation was $1.9 \%$ at $5.2 \mathrm{mmol} / \mathrm{l}$. The assay detection limit was $0.5 \mathrm{mmol} / \mathrm{l}$.

HOB was measured by an enzymatic method ${ }^{8}$ adapted for the Hitachi 911 analyser. The between-run coefficients of variation were $3.9 \%$ and $2.6 \%$ at 0.85 and $2.50 \mathrm{mmol} / \mathrm{l}$ respectively. The assay detection limit was $0.05 \mathrm{mmol} / \mathrm{l}$.

Insulin was measured by a two-site immunoenzymometric assay on the AIA-600 random access automated enzyme immunoassay system (Eurogenetics UK Ltd, Redditch, Worcestershire, UK). The between-run coefficient of variation was $<6 \%$ across the analytical range of $2-350 \mathrm{mU} / \mathrm{l}$. The assay detection limit was $2.0 \mathrm{mU} / \mathrm{l}$.

Cortisol was measured by a chemiluminescent enzyme immunoassay on the Immulite analyser (DPC-UK, Glyn Rhonwy, Gwynedd, Wales, UK) until 30 July $1998(\mathrm{n}=18)$. Between-run coefficients of variation were $9.4 \%, 4.7 \%$, and $4.4 \%$ at 97,479 , and $816 \mathrm{nmol} / \mathrm{l}$ respectively. After 30 July 1998, cortisol was measured by a competitive immunoassay using heterogeneous magnetic separation technology on the Immuno 1 analyser (Bayer plc, Newby, Berks, UK, $\mathrm{n}=45$ ). Between-assay coefficients of variation were $7.7 \%, 3.4 \%$, and $2.9 \%$ at 79,538 , and $752 \mathrm{nmol} / \mathrm{l}$ respectively. The assay detection limit for both cortisol methods was $50 \mathrm{nmol} / \mathrm{l}$. For 90 samples with cortisol concentrations up to $1200 \mathrm{nmol} / \mathrm{l}$, the relation between the two methods was: $y=1.03 x-15$ $\left(r^{2}=0.99\right)$, where $x$ and $y$ were cortisol results (in nmol/l) using the Immulite and Immuno 1 methods respectively. The mean difference between the two methods was $3 \mathrm{nmol} / \mathrm{l}$ and was not significantly different from zero.

GH was measured by a two-site chemiluminescent enzyme immunoassay on the Immulite analyser. Between-run coefficients of variation were $6.6 \%, 3.5 \%, 4.4 \%$, and $4.5 \%$ at $1.8,7.2,12.1$, and $21.7 \mathrm{mU} / \mathrm{l}$ respectively. The analytical range was $0.3-104 \mathrm{mU} / \mathrm{l}$.

\section{Data analysis}

Results below the assay detection limit were expressed as the assay detection limit. Similarly GH results greater than $104 \mathrm{mU} / \mathrm{l}$ were expressed as $104 \mathrm{mU} / \mathrm{l}$. Non-parametric statistics were used throughout since the data did not conform to a Gaussian distribution. Data were expressed as median (range). Differences between groups were assessed by the Mann-Whitney test. Spearman rank correlations were used to explore relations between variables. Statistical significance was accepted at $\mathrm{p}<0.05$.

\section{RESULTS}

\section{Hypoglycaemic group}

Thirty six samples were obtained from 30 patients at the time of documented hypoglycaemia. Median glucose was $1.9 \mathrm{mmol} / \mathrm{l}$ (range $<0.5-2.4 \mathrm{mmol} / \mathrm{l}$ ). Cortisol was analysed in all 36 samples whereas GH results were available in only $21 / 36$ samples because of sample volume constraints. Cortisol showed no correlation with glucose $\left(r_{\mathrm{s}}-0.07, \mathrm{p}=0.70\right)$ but a marked positive correlation with age $\left(r_{\mathrm{s}}+0.66, \mathrm{p}<0.0001\right.$, fig lA). Similarly, GH showed no correlation with glucose $\left(r_{\mathrm{s}}-0.27, \mathrm{p}=0.24\right)$ but a marked inverse correlation with age $\left(r_{\mathrm{s}}-0.65, \mathrm{p}=0.001\right.$, fig $\left.1 \mathrm{~B}\right)$. For further analysis, the hypoglycaemic group was sub-divided into patients younger than 3 months and older than 6 months. Table 1 shows the medians and ranges of age, glucose, HOB, and hormonal results in these two age groups. There was no difference in glucose between the two age groups, but insulin and GH were higher $(\mathrm{p}=0.02$ and $\mathrm{p}<0.01$ respectively) and cortisol was lower $(p<0.0001)$ in the younger compared with the older group. 

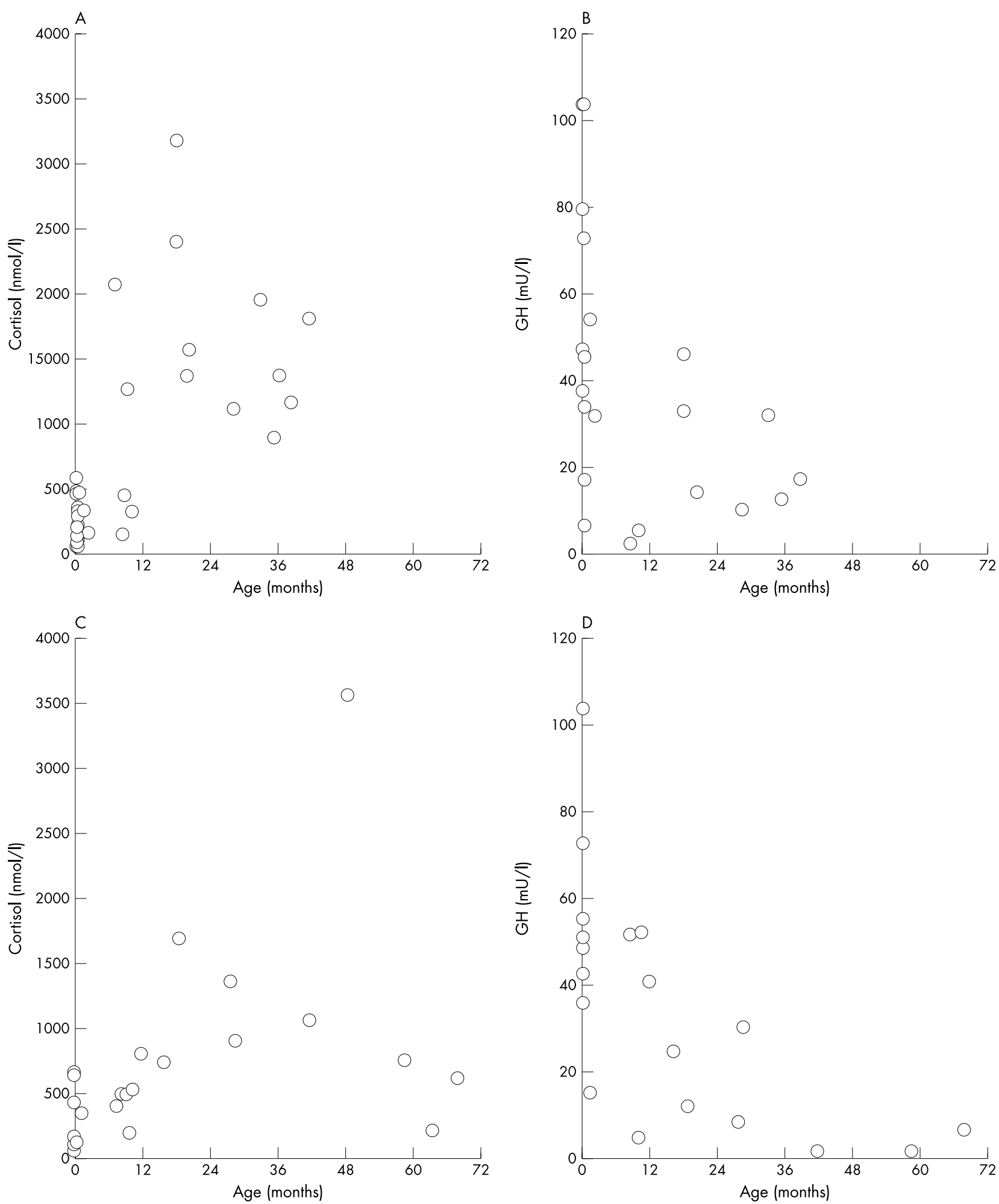

Figure 1 Relation of cortisol and GH to age in 63 samples collected from 56 paediatric subjects investigated for suspected hypoglycaemia. (A) Cortisol in hypoglycaemic subjects (glucose $<2.5 \mathrm{mmol} / \mathrm{l}$ ). The three samples with cortisol $<500 \mathrm{nmol} / \mathrm{l}$ in infants aged 8-10 months were from patients with persistent hyperinsulinism or reactive hypoglycaemia respectively (see text). (B) GH in hypoglycaemic subjects. The two samples with GH $<10 \mathrm{mU} / \mathrm{l}$ in infants aged 8-10 months were from patients with persistent hyperinsulinism or reactive hypoglycaemia respectively (see text). (C) Cortisol in non-hypoglycaemic subjects (glucose $\geqslant 2.5 \mathrm{mmol} / \mathrm{l}$ ). (D) $\mathrm{GH}$ in non-hypoglycaemic subjects.

Infants younger than 3 months $(n=16)$

Hypoglycaemia was ascribed to the following causes: persistent hyperinsulinaemic hypoglycaemia of infancy $(\mathrm{n}=1$, treated with diazoxide and chlorothiazide), transient hyperinsulinaemic hypoglycaemia of infancy $(n=8$, of whom three were treated with diazoxide and chlorothiazide \pm somatostatin), sepsis $(n=3$, of whom two were premature infants), and necrotising enterocolitis $(\mathrm{n}=2$, both of whom were premature). Seven of the infants had a birth weight $<10$ th centile for gestational age, but in only one of these was 
Table 1 Glucose, HOB, and hormone levels, divided according to age and glycaemic status at the time of sampling in 63 samples collected from 56 neonates, infants, and children investigated for suspected hypoglycaemia

\begin{tabular}{|c|c|c|c|c|c|c|c|}
\hline & \multicolumn{3}{|c|}{ Hypoglycaemic group } & \multicolumn{3}{|c|}{ Non-hypoglycaemic group } & \multirow[b]{2}{*}{ p value ${ }^{*}$} \\
\hline & $\mathbf{n}$ & Median & Range & $\mathbf{n}$ & Median & Range & \\
\hline \multicolumn{8}{|l|}{ Infants $<3$ months } \\
\hline Age (days) & 21 & 9 & $2-70$ & 12 & 4 & $2-40$ & 0.07 \\
\hline Glucose (mmol/l) & 21 & 2.0 & $<0.5-2.4$ & 12 & 3.2 & $2.8-14.9$ & N/A \\
\hline $\mathrm{HOB}(\mathrm{mmol} / \mathrm{l})$ & 12 & $<0.05$ & $<0.05-6.70$ & 5 & $<0.05$ & $<0.05-0.64$ & 0.96 \\
\hline Insulin (mU/l) & 19 & 2.4 & $<2.0-25.5$ & - & - & - & N/A \\
\hline Cortisol (nmol/l) & 21 & 205 & $<50-584$ & 12 & 116 & $<50-665$ & 0.52 \\
\hline $\mathrm{GH}(\mathrm{mU} / \mathrm{l})$ & 12 & 46.5 & $6.6->104$ & 9 & 51.2 & $15.3->104$ & 0.60 \\
\hline \multicolumn{8}{|c|}{ Infants and children $>6$ months } \\
\hline Age (months) & 15 & 20.0 & $7.0-41.7$ & 15 & 18.6 & $7.5-68.0$ & 0.62 \\
\hline Glucose (mmol/l) & 15 & 1.9 & $0.8-2.4$ & 15 & 3.6 & $2.6-10.4$ & N/A \\
\hline $\mathrm{HOB}(\mathrm{mmol} / \mathrm{l})$ & 12 & 4.23 & $<0.05-7.38$ & 11 & 3.00 & $<0.05-9.66$ & 0.53 \\
\hline Insulin (mU/I) & 12 & $<2.0$ & $<2.0-5.3$ & - & - & - & N/A \\
\hline Cortisol (nmol/l) & 15 & 1370 & $142-3190$ & 15 & 736 & $194-3560$ & 0.05 \\
\hline $\mathrm{GH}(\mathrm{mU} / \mathrm{l})$ & 9 & 14.3 & $2.5-46.1$ & 11 & 12.1 & $1.5-52.3$ & 0.82 \\
\hline
\end{tabular}

*Mann-Whitney $\mathrm{U}$ test comparing hypoglycaemic and non-hypoglycaemic groups.

N/A, not applicable.

relatively low birth weight the only risk factor One infant of appropriate weight for gestation had poor feeding as the only risk factor (single episode of hypoglycaemia). Median gestational age at birth was 37 weeks (range 24-39 weeks). Only three infants were significantly premature $(<35$ weeks gestational age). Median birth weight was $2.41 \mathrm{~kg}$ (range $0.65-4.62 \mathrm{~kg}$ ). The onset of hypoglycaemia occurred in most infants in the first day of life (median, range $<1$ h to day 46). Fourteen of 16 infants required intravenous glucose infusion to maintain normoglycaemia. In these infants, maximal glucose requirement was $13.3 \mathrm{mg} / \mathrm{kg} / \mathrm{min}$ (median; range $8.2-16.9 \mathrm{mg} / \mathrm{kg} / \mathrm{min}$ ) and occurred on day 4 of life (median; range 2-19). The hypoglycaemic tendency resolved by day 18 (median; range day 7-71, excluding the patient with persistent hyperinsulinism). Twenty one samples were collected from these 16 infants at the time of documented hypoglycaemia. One infant had three hypoglycaemic screens carried out during separate hypoglycaemic episodes, three infants had two screens, and the remainder had a single screen.

Only half the infants had cortisol concentrations greater than $200 \mathrm{nmol} / \mathrm{l}$ during hypoglycaemia and five had levels below $100 \mathrm{nmol} / \mathrm{l}$ (table 1, fig lA). However, most had GH levels greater than $30 \mathrm{mU} / \mathrm{l}$. The two infants who had lower $\mathrm{GH}$ levels of $6.6 \mathrm{mU} / \mathrm{l}$ and $17.3 \mathrm{mU} / \mathrm{l}$ during hypoglycaemia achieved levels of $28.4 \mathrm{mU} / \mathrm{l}$ and $34.1 \mathrm{mU} / \mathrm{l}$ respectively on other occasions. There was a tendency to higher GH levels in those infants whose birth weight was $<10$ th centile for gestation, or premature (gestational age $<35$ weeks, median GH 73.1 mU/l) compared with those who were of appropriate weight for gestation and born closer to term (GH median $34.1 \mathrm{mU} / \mathrm{l}, \mathrm{p}=0.07$ ) but no difference in cortisol or insulin $(p=0.22$ and 0.66 respectively). Cortisol and GH did not differ between infants who were hyperinsulinaemic at the time of sampling compared with those who were not $(\mathrm{p}=0.35$ and 0.59 respectively) .

Most infants in this age group had direct or indirect evidence of hyperinsulinism. Median insulin was $2.4 \mathrm{mU} / \mathrm{l}$ (table 1) and median HOB (in those infants in which it was measured) was $<0.05 \mathrm{mmol} / \mathrm{l}$ (table 1). Insulin was detectable in $11 / 21$ samples, below the detection limit $(<2.0 \mathrm{mU} / \mathrm{l})$ in $8 / 21$ samples, and not measured in $2 / 21$ samples. Five of the eight subjects with undetectable insulin at the time of sampling nevertheless had clear evidence of an increased glucose requirement $(10-20 \mathrm{mg} / \mathrm{kg} / \mathrm{min})$ to maintain normoglycaemia; HOB was suppressed below $0.05 \mathrm{mmol} / \mathrm{l}$ in $5 / 8$, was $0.70 \mathrm{mmol} / \mathrm{l}$ in one 46 day old infant with sepsis, and was not measured in two samples. Both samples in which there was no HOB result were from neonates who had had demonstrable hyperinsulinaemia on a separate occasion. In the samples in which insulin was not measured, one was from a ketotic neonate (HOB $6.70 \mathrm{mmol} / \mathrm{l}$ ) and the other did not have an HOB measurement but was from a premature infant born at 29 weeks gestational age with sepsis and a maximal glucose requirement of $8.2 \mathrm{mg} / \mathrm{kg} / \mathrm{min}$.

Infants and children older than 6 months $(n=14)$ Hypoglycaemia was ascribed to the following causes: intercurrent illness with vomiting $(n=7)$, fatty acid oxidation defects $(n=3)$, persistent hyperinsulinism $(n=1)$, congenital central hypoventilation syndrome ("Ondine's curse") with gut motility problems and reactive hypoglycaemia after feeding $(\mathrm{n}=1)$, and postoperative hepatic dysfunction following cardiac surgery $(n=1)$. In one 20 month old dysmorphic infant with hypotonia and failure to thrive, no cause was found for her recurrent episodes of ketotic hypoglycaemia when unwell; fatty acid oxidation defects were specifically excluded. Fifteen samples were collected from these 14 patients at the time of documented hypoglycaemia.

In this older group, most patients (12/15) had cortisol levels greater than $800 \mathrm{nmol} / \mathrm{l}$ during hypoglycaemia. The remaining three samples in which cortisol was less than $500 \mathrm{nmol} / \mathrm{l}$ were from the two infants aged 8-10 months with either persistent or reactive hyperinsulinaemia (fig 1A). Only 4/9 patients had GH levels greater than $15 \mathrm{mU} / \mathrm{l}$ during hypoglycaemia. The two samples in which GH response to hypoglycaemia was less than $10 \mathrm{mU} / \mathrm{l}$ were also from the two infants aged $8-10$ months with either persistent or reactive hyperinsulinaemia (fig 1B).

Median insulin was $<2.0 \mathrm{mU} / \mathrm{l}$ (table 1 ), significantly lower than in the younger group $(p=0.02)$. Median HOB was $4.23 \mathrm{mmol} / \mathrm{l}$, significantly higher than in the younger group $(\mathrm{p}<0.01)$. Insulin was detectable in $2 / 15$ samples ( $4.4 \mathrm{mU} / \mathrm{l}$ when glucose was $2.4 \mathrm{mmol} / \mathrm{l}$ in the 10 month old infant with persistent hyperinsulinism, $5.3 \mathrm{mU} / \mathrm{l}$ when glucose was $1.8 \mathrm{mmol} / \mathrm{l}$ in the 8 month old infant with reactive hypoglycaemia). Insulin was below the detection limit in 10/15 samples. Insulin was not measured in 3/15 samples: in two, hyperinsulinism was excluded by appropriate increases in HOB ( 3.46 and $3.07 \mathrm{mmol} / \mathrm{l}$ respectively), while in the third, there was insufficient sample for insulin measurement. 


\section{Non-hypoglycaemic group}

Cortisol was analysed in all 27 samples whereas GH results were available in only 20/27 samples because of sample volume constraints. In the non-hypoglycaemic group (as in the hypoglycaemic group), cortisol showed no correlation with glucose $\left(r_{\mathrm{s}}-0.11, \mathrm{p}=0.58\right)$ but a marked positive correlation with age $\left(r_{\mathrm{s}}+0.68, \mathrm{p}<0.0001\right.$, fig $\left.\mathrm{lC}\right)$. Similarly, GH showed no correlation with glucose $\left(r_{\mathrm{s}}-0.04, \mathrm{p}=0.89\right)$ but a marked negative correlation with age $\left(r_{\mathrm{s}}-0.75\right.$, $\mathrm{p}<0.0001$, fig 1D). To match the hypoglycaemic group, the non-hypoglycaemic subjects were also divided into patients younger than 3 months and older than 6 months (there were no non-hypoglycaemic infants aged between 3 and 6 months). Table 1 summarises the age, glucose, HOB, cortisol, and GH results in the two age groups. There was no difference in glucose between the two age groups $(\mathrm{p}=1.00)$, but GH was higher $(\mathrm{p}<0.01)$ and cortisol was lower $(p<0.001)$ in the younger compared with the older age group.

\section{Infants younger than 3 months $(n=11)$}

A total of 12 samples were collected from these 11 infants at the time of suspected hypoglycaemia. Cortisol levels were not significantly different from age matched infants who were hypoglycaemic at the time of sampling ( $p=0.52$, table 1$)$. There was no difference in cortisol between the infants with glucose below and above $3.2 \mathrm{mmol} / \mathrm{l}$, the glycaemic threshold for cortisol secretion in adults ${ }^{5}(p=0.5)$. GH did not differ from the hypoglycaemic infants and exceeded $30 \mathrm{mU} / \mathrm{l}$ in all samples but one. There was no difference in GH between the infants with glucose below and above $3.7 \mathrm{mmol} / \mathrm{l}$, the glycaemic threshold for GH secretion in adults ${ }^{5}(\mathrm{p}=1.0)$.

Insulin was not measured. HOB (when measured) was usually below the detection limit (table 1).

Infants and children older than 6 months $(n=15)$ Cortisol was significantly lower in the non-hypoglycaemic subjects compared with age matched subjects who were hypoglycaemic at the time of sampling $(p=0.05)$. Nevertheless, the five subjects with glucose levels $\geqslant 2.5 \mathrm{mmol} / \mathrm{l}$ but below the glycaemic threshold of $3.2 \mathrm{mmol} / \mathrm{l}$ for cortisol secretion in adults ${ }^{5}$ had a much higher median cortisol ( $1362 \mathrm{nmol} / \mathrm{l}$, range 497-3560 nmol/l) compared with the 10 subjects who had glucose levels at or above that threshold $(573 \mathrm{nmol} / \mathrm{l}$, range $194-1062 \mathrm{nmol} / \mathrm{l}$, $\mathrm{p}=0.03$ ).

GH was similar overall in the non-hypoglycaemic and hypoglycaemic groups $(p=0.82$, table 1$)$. Nevertheless, the six subjects in the "non-hypoglycaemic" group with glucose levels below the glycaemic threshold of $3.7 \mathrm{mmol} / \mathrm{l}$ for $\mathrm{GH}$ secretion in adults ${ }^{5}$ had a much higher median $\mathrm{GH}(27.6 \mathrm{mU} /$ l; range 8.4-52.3 mU/l) compared with the five children who had glucose levels at or above that threshold $(4.8 \mathrm{mU} / \mathrm{l}$; range 1.5-40.9 mU/l, p=0.05). After exclusion of a single child (glucose $10.4 \mathrm{mmol} / \mathrm{l}, \mathrm{GH} 40.9 \mathrm{mU} / \mathrm{l}$ ), who had been hypoglycaemic one hour earlier (laboratory glucose $2.4 \mathrm{mmol} / \mathrm{l}$ ) but had been treated with glucose before the hypoglycaemic screen was carried out, all children with glucose $\geqslant 3.7 \mathrm{mmol} / \mathrm{l}$ had GH levels $<7 \mathrm{mU} / \mathrm{l}$, significantly lower than in those with glucose $<3.7 \mathrm{mmol} / \mathrm{l}(\mathrm{p}=0.01)$.

Insulin was not measured. HOB was variable with a distribution similar to that observed in the hypoglycaemic group $(\mathrm{p}=0.53$, table 1$)$. HOB showed no differences between subjects with glucose levels above or below the glycaemic thresholds of either 3.2 or $3.7 \mathrm{mmol} / \mathrm{l}(\mathrm{p}>0.5)$.

\section{DISCUSSION}

In our study, most hypoglycaemic infants younger than 3 months had evidence of hyperinsulinism in terms of increased glucose requirement, detectable plasma insulin, and/or undetectable HOB at the time of hypoglycaemia, although in only one infant was this persistent. Just under half were relatively SGA infants, consistent with the recognised susceptibility of such infants to hypoglycaemia, ${ }^{3}{ }^{10}$ and three (including one of the SGA infants) were preterm. However, there was no difference in measured insulin between those who were born $<10$ th centile for weight or preterm compared with those born $\geqslant 10$ th centile for weight at $>35$ weeks gestation. By contrast, only two infants older than 6 months (and no children) had evidence of hyperinsulinism. One was the infant with persistent hyperinsulinism and the other was an infant with "Ondine's curse", gut motility problems, and reactive hypoglycaemia, an association that has been previously described. ${ }^{11}$ In the older age group, hypoglycaemia appeared in most cases to be secondary to prolonged fasting during intercurrent illness, although there were also three patients with fatty acid oxidation defects.

\section{Cortisol responses}

In adults, the glycaemic threshold for cortisol secretion is around $3.2 \mathrm{mmol} / \mathrm{l}$, established during stepped reductions in plasma glucose under hyperinsulinaemic clamp conditions. ${ }^{5}$ In 28 children, aged $0.9-10$ years, without evidence of defects in the hypothalamic-pituitary-adrenal axis, who were subjected to an insulin induced hypoglycaemia test for diagnostic purposes, we have previously established that the cortisol response to hypoglycaemia (glucose $\leqslant 2.0 \mathrm{mmol} / \mathrm{l}$ ) was 550 $900 \mathrm{nmol} / \mathrm{l}$ (5-95th centiles). ${ }^{11 a}$

By definition, the young ( $<3$ months) spontaneously hypoglycaemic infants in our study group all had plasma glucose levels $<2.5 \mathrm{mmol} / \mathrm{l}$, with a median of $2.0 \mathrm{mmol} / \mathrm{l}$. However, they showed poor cortisol responses even when severely hypoglycaemic, with only one infant displaying a cortisol response greater than $550 \mathrm{nmol} / \mathrm{l}$. Indeed, plasma cortisol did not differ significantly between hypoglycaemic and non-hypoglycaemic infants, nor between infants with glucose above or below the adult glycaemic threshold of $3.2 \mathrm{mmol} / \mathrm{l}$, in agreement with a previous study on hypoglycaemic and non-hypoglycaemic SGA infants ${ }^{10}$ and a preliminary report on six hyperinsulinaemic neonates which suggested that such infants might have a delayed and possibly inadequate response to hypoglycaemia. ${ }^{12}$ We observed no difference in cortisol response between hypoglycaemic infants born $<10$ th centile for weight or preterm and infants born $\geqslant 10$ th centile for birth weight at $>35$ weeks gestation, nor between hyperinsulinaemic and non-hyperinsulinaemic infants, suggesting that most spontaneously hypoglycaemic infants produce poor cortisol responses to hypoglycaemia, regardless of their gestational age, intrauterine growth, or insulin status at the time of sampling. By contrast, a previous study of preterm infants subjected to a controlled fast before discharge found that the five infants who developed hypoglycaemia had a higher mean cortisol than those infants who remained normoglycaemic throughout. $^{13}$

Our observation of a poor cortisol response to spontaneous hypoglycaemia in young infants contrasts sharply with the marked cortisol response in spontaneously hypoglycaemic older subjects. Interestingly, the only exceptions were two older infants aged 8 and 10 months with persistent or reactive hyperinsulinism, who had cortisol responses $<500 \mathrm{nmol} / \mathrm{l}$ to glucose levels of $1.6-2.4 \mathrm{mmol} / \mathrm{l}$. All other hypoglycaemic older subjects had cortisol responses $\geqslant 896 \mathrm{nmol} / \mathrm{l}$. There was indirect evidence that older subjects had a glycaemic threshold for cortisol secretion similar to that in adults $(3.2 \mathrm{mmol} / \mathrm{l})$ since cortisol responses were 
much greater when glucose was below compared with above that threshold.

What is the reason for the discrepancy in cortisol responses between young infants and older infants and children? There was no evidence that the infants in our study had pituitary or adrenal insufficiency. They had appropriate GH secretion for age, normal electrolytes, and, in all cases except for the infant with persistent hyperinsulinism, the hypoglycaemic tendency resolved and the subsequent clinical course was not suggestive of pituitary or adrenal impairment. In the three hypoglycaemic infants in whom it was measured, ACTH was $\leqslant 7 \mathrm{mU} / \mathrm{l}$, excluding primary adrenal insufficiency. Term neonates undergoing surgery are able to mount appropriate cortisol stress responses of around $600 \mathrm{nmol} / \mathrm{l} .{ }^{14}{ }^{15} \mathrm{Ill}$ preterm infants can also mount impressive cortisol stress responses during the first week of life, especially in association with clinical complications such as intraventricular haemorrhage. ${ }^{16}$ However, very premature infants may have an impaired cortisol response to illness, ${ }^{17}{ }^{18}$ although they are able to mount an appropriate cortisol response to corticotrophin releasing hormone $(\mathrm{CRH})$ or $\mathrm{ACTH}$, either because they have inadequate hypothalamic secretion of $\mathrm{CRH}$ or because they are unable to recognise the stress of illness centrally. ${ }^{17}$ Only one infant in our study was extremely premature ( 24 weeks gestation), with sepsis and necrotising enterocolitis, glucose $2.0 \mathrm{mmol} / \mathrm{l}$, undetectable insulin, and a cortisol of $158 \mathrm{nmol} / \mathrm{l}$ consistent with either of these hypotheses. It is possible that, in some infants with recurrent hypoglycaemic episodes, ACTH reserve may be depleted. However, this seems unlikely since even preterm neonates can maintain very high levels of circulating cortisol over a prolonged period in response to the stress of illness. ${ }^{16}$ An alternative hypothesis might be that, in hypoglycaemic infants, the hypothalamic-pituitary response to hypoglycaemic stress is diminished because they have experienced relatively low ambient glucose concentrations from birth. Indeed, the apparent lack of a hypothalamic-pituitary stress response to hypoglycaemia may be part of a wider physiological adaptation to the lower glucose levels after birth resulting from the onset of intermittent feeding during extrauterine life. This hypothesis is also consistent with a report of lower glycaemic thresholds for counter-regulatory hormone release following intensive insulin therapy in young patients with insulin dependent diabetes. ${ }^{19}$ The only two older infants to have suboptimal cortisol responses $<500 \mathrm{nmol} / \mathrm{l}$ were also hyperinsulinaemic. All others had marked cortisol responses to hypoglycaemic stress, although the stress of illness may also have played a part.

\section{GH responses}

In adults, the glycaemic threshold for GH secretion is around $3.7 \mathrm{mmol} / \mathrm{l} .^{5}$ For our laboratory and local paediatric population, the cut-off for defining an appropriate GH response to the insulin induced hypoglycaemia test in children is $15 \mathrm{mU} / \mathrm{l}$. Consensus guidelines for the diagnosis of $\mathrm{GH}$ deficiency in neonates suggest a cut-off of twice that in the older paediatric population, ${ }^{20}$ namely $30 \mathrm{mU} / \mathrm{l}$.

In infants younger than 3 months, $\mathrm{GH}$ exceeded $30 \mathrm{mU} / \mathrm{l}$ in most samples, regardless of whether or not they were hypoglycaemic at the time of sampling. The GH levels observed in our study span the range (nadir to peak) of the unstimulated pulsatile GH levels previously reported for this age group, ${ }^{21}{ }^{22}$ and are similar to the levels observed in both normoglycaemic and hypoglycaemic preterm infants fasted prior to discharge from hospital. ${ }^{13}$ In our study infants born $<10$ th centile for weight or preterm had a tendency to higher GH levels than infants born $\geqslant 10$ th centile for birth weight at $>35$ weeks gestation, consistent with earlier reports. ${ }^{23}$
By contrast, older infants and children in our study had relatively poor responses to spontaneous hypoglycaemia, with less than half of older subjects having a $\mathrm{GH}>15 \mathrm{mU} / \mathrm{l}$, although most had levels $>10 \mathrm{mU} / \mathrm{l}$. All but one of the patients with $\mathrm{GH}<15 \mathrm{mU} / \mathrm{l}$ had normal growth, making pituitary insufficiency unlikely. The only exception was the dysmorphic girl with hypotonia (see Results) whose height and weight were below the third centile; her GH was $14.3 \mathrm{mU} / \mathrm{l}$ during hypoglycaemia, but her insulin-like growth factor I was appropriate for age and sex. The only older subjects who had $\mathrm{GH}$ responses $<10 \mathrm{mU} / \mathrm{l}$ were the two hyperinsulinaemic infants who also had poor cortisol responses (see above). This is consistent with our hypothesis of a diminished hypothalamic-pituitary response to hypoglycaemic stress in these infants. A preliminary report on 10 children who became hypoglycaemic during a controlled fast described even lower GH responses than in our study, perhaps because (unlike our study) the fast was carried out when the children were well. ${ }^{24}$ In our study, there was indirect evidence that older subjects had a glycaemic threshold for GH secretion similar to that in adults $(3.7 \mathrm{mmol} / \mathrm{l}$ ) since GH responses were greater when glucose was below compared with above that threshold.

We recognise that only one sample was collected during each hypoglycaemic episode, that its timing in relation to the onset of hypoglycaemia is unknown, and that, for ethical reasons, sequential samples could not be obtained to determine the evolution of any counter-regulatory response prior to correction of the hypoglycaemia by glucose infusion. It is therefore possible that peak hormonal responses were missed. This may particularly apply to GH: a recent audit of the insulin induced hypoglycaemia test in our laboratory revealed that the mode of the peak GH response occurred at around 40 minutes after the glucose nadir. Furthermore, the stimulus to GH secretion may depend as much on the rate of decrease of plasma glucose-which may be slow in spontaneous hypoglycaemia-as the absolute glucose concentration reached. These caveats also apply to those infants and children who were found not to be hypoglycaemic at the time the hypoglycaemia screen was performed but some of whom had been hypoglycaemic (confirmed by laboratory glucose measurement) 1-2 hours earlier.

In summary, hyperinsulinism was the predominant cause of hypoglycaemia in young infants whereas intercurrent infection was the commonest cause in older infants and children. We have shown that cortisol and GH responses to spontaneous hypoglycaemia are highly age dependent. Young infants mounted poor cortisol responses to hypoglycaemia compared with the very marked responses observed in older infants and children, and our data suggest that this may have been related to a tendency to recurrent hypoglycaemia from birth in the young infants. Conversely, GH in young infants was high regardless of glycaemic status but GH response to hypoglycaemia in older subjects was variable. Older infants and children appeared to have glycaemic thresholds for cortisol and GH release similar to those of adults. Cortisol measurement during hypoglycaemia is a more informative test of pituitary and adrenal function in subjects older than 6 months than in young infants in whom GH measurement and further investigation (for example, an ACTH stimulation test) may be required to exclude pituitary and adrenal insufficiency.

\section{ACKNOWLEDGEMENTS}

We thank the staff of Clinical Biochemistry, Royal Infirmary, Edinburgh for the cortisol and GH measurements and the staff of Clinical Biochemistry, Western General Hospital, Edinburgh for the insulin measurements. We would also like to thank all our clinical colleagues whose patients contributed to the study. 


\section{Authors' affiliations}

P M Crofton, Department of Paediatric Biochemistry, Royal Hospital for

Sick Children, Edinburgh, UK

P C Midgley, Department of Child Life and Health, Reproductive and

Developmental Sciences, University of Edinburgh, UK

\section{REFERENCES}

1 Stanley CA, Baker L. The causes of neonatal hypoglycemia. N Engl J Med 1999:340:1200-1.

2 Artavia-Loria E, Chaussain JL, Bougneres PF, et al. Frequency of hypoglycemia in children with adrenal insufficiency. Acta Endocrinol Suppl (Copenh) 1986;279:275-8.

3 Lafranchi S. Hypoglycemia of infancy and childhood. Pediatr Clin North Am 1987:34:961-82.

4 Morris AAM, Thekekara A, Wilks Z, et al. Evaluation of fasts for investigating hypoglycaemia or suspected metabolic disease. Arch Dis Child 1996;75:115-19.

5 Schwartz NS, Clutter WE, Shah SD, et al. Glycemic thresholds for activation of glucose counterregulatory systems are higher than the threshold for symptoms. J Clin Invest 1987;79:777-81.

6 Hindmarsh PC, Swift PGF. An assessment of growth hormone provocation tests. Arch Dis Child 1995;72:362-8.

7 Petersen KE. ACTH in normal children and children with pituitary and adrenal diseases. II. Plasma ACTH (cortisol and growth hormone) values during insulin hypoglycaemia-patients with idiopathic hypopituitarism and intracranial tumour. Acta Paediatr Scand 1984:73:372-8.

8 Williamson DH, Mellanby J, Krebs HA. Enzymic determination of $D(-) / B$ hydroxybutyric acid and acetoacetic acid in blood. Biochem J 1962;82:90-6.

9 Collins JE, Leonard JV, Teale D, et al. Hyperinsulinaemic hypoglycaemia in small for dates babies. Arch Dis Child 1990;65:1118-20.

10 Hawdon JM, Weddell A, Aynsley-Green A, et al. Hormonal and metabolic response to hypoglycaemia in small for gestational age infants. Arch Dis Child 1993;68:269-73.

11 O'Donnell JG. Infantile hypoglycaemia caused by "dumping" [abstract]. In Martin SM, Halloran SP, Green AJE, eds. Proceedings of the ACB National Meeting 1994:89.
1 la Crofton PM, Don-Wauchope AC, Bath LE, et al. Cortisol responses to the insulin hypoglycaemia test in children. Horm Res 2004;61:92-7.

12 Hussain K, Hindmarsh P, Aynsley-Green A. Neonatal hyperinsulinism (HI) is associated with abnormal cortisol responses to hypoglycaemia (HY) [abstract]. Horm Res 2000;53(suppl 2):26.

13 Hume R, McGeechan A, Burchell A. Failure to detect preterm infants at risk of hypoglycemia before discharge. J Pediatr 1999:134:499-502.

14 Anand KJS, Sippell WG, Schofield NM, et al. Does halothane anaesthesia decrease the metabolic and endocrine stress responses of newborn infants undergoing operation? BMJ 1988;296:668-72.

15 Anand KJS, Hansen DD, Hickey PR. Hormonal-metabolic stress responses in neonates undergoing cardiac surgery. Anesthesiology 1990;73:661-70

16 Hughes D, Murphy JF, Dyas J, et al. Blood spot glucocorticoid concentrations in ill preterm infants. Arch Dis Child 1987;62:1014-18.

17 Hanna CE, Keith LD, Colasurdo MA, et al. Hypothalamic pituitary adrenal function in the extremely low birth weight infant. $J$ Clin Endocrinol Metab 1993;76:384-7

18 Scott SM, Watterberg KL. Effect of gestational age, postnatal age, and illness on plasma cortisol concentrations in premature infants. Pediatr Res 1995; 37:1 12-16.

19 Amiel SA, Sherwin RS, Simonson DC, et al. Effect of intensive insulin therapy on glycemic thresholds for counterregulatory hormone release. Diabetes 1988;37:901-7.

20 GH Research Society. Consensus guidelines for the diagnosis and treatment of growth hormone (GH) deficiency in childhood and adolescence: summary statement of the GH Research Society. J Clin Endocrinol Metab 2000:85:3990-3.

21 Vigneri R, D'Agata R. Growth hormone release during the first year of life in relation to sleep-wake periods. J Clin Endocrinol Metab 1971;33:561-3.

22 Miller JD, Esparza A, Wright NM, et al. Spontaneous growth hormone release in term infants: changes during the first four days of life. J Clin Endocrinol Metab 1993;76:1058-62.

23 Wollmann HA. Growth hormone and growth factors during perinatal life. Horm Res 2000:53(suppl 1):50-4.

24 Hindmarsh P, Hussain K, Aynsley-Green A. Spontaneous hypoglycaemia (SHY) in childhood is accompanied by paradoxical cortisol and growth hormone responses [abstract]. Horm Res 2000;53(suppl 2):35. 